\title{
CONFERÊNCIA: \\ Currículos, apreciação musical e culturas brasileiras
}

Vanda L. Bellard Freire

Apreciação musical é um tema que não tem ocupado, com a freqüência e com a ênfase necessárias, as discussões curriculares em nossa área, exceto em algumas situações específicas.

Por outro lado, freqüentemente a apreciação musical é tratada de forma superficial ou equivocada, confundindo-se, muitas vezes, com o simples "gostar" da música ou com uma escuta que não contribui para a construção do conhecimento musical. Com base nessas considerações iniciais, esta conferência pretende abordar a apreciação musical como uma atividade efetivamente comprometida com a construção do conhecimento musical, em uma perspectiva curricular, e utilizando como material principal para a escuta o repertório brasileiro.

Inicialmente, situamos nossa posição em relação à teoria curricular e à filosofia da educação, colocando-nos em alinhamento com a pedagogia crítico-social, que identifica $o$ currículo como um espaço contestado, ou de conflito, segundo uma ótica dialética. Nessa perspectiva, podemos considerar que um dos 
níveis de conflito a ser considerado em qualquer reflexão curricular é o da contradição de culturas brasileiras, e, conseqüentemente, de suas diversas formas de expressão. Utilizaremos neste texto, intencionalmente, a expressão "culturas brasileiras", por entendermos que não temos uma cultura homogênea, mas um tecido cultural complexo e diversificado. No Brasil, conforme já analisamos em trabalho anterior (Freire, 1994), têm prevalecido currículos que se modelam, prioritariamente, segundo o paradigma que Domingues (1986) identifica como técnico-linear, e que refletem uma concepção de educação que Saviani (1989) identifica como humanista tradicional. São currículos cuja ênfase está no professor, considerado detentor do conhecimento a ser transmitido. 0 objetivo principal desses currículos é a habilitação técnica, visando à adaptação do indivíduo à sociedade.

Nessa visão curricular, que tem prevalecido nos currículos de música no Brasil, cabe observar que as músicas representativas das culturas brasileiras têm ocupado pouco ou nenhum espaço, o que é facilmente observável através do repertório utilizado.Se tomarmos como exemplo os currículos dos Cursos Superiores de Música, veremos que, habitualmente, eles têm-se centrado na cultura "tradicional" européia, principalmente dos séculos XVIII e XIX, em cujos modelos são apoiadas as técnicas, conteúdos, concepções, etc, abordados nos currículos. 
Um exemplo corriqueiro que podemos citar, e que ilustra a discriminação com as nossas próprias culturas, é o da disciplina História da Música, que, com esse nome, focaliza somente (ou quase exclusivamente) a música estrangeira, pois as nossas músicas integram o conteúdo de outra disciplina, muitas vezes optativa, denominada História da Música Brasileira ( neste caso, há necessidade de designarmos a música como brasileira, mas no caso anterior não se constata a necessidade de especificar que o objetivo é tratar da música estrangeira). Observa-se, ainda, que as manifestações musicais classificadas como "populares" são freqüentemente excluídas ou sub-valorizadas, o que agrava o processo de discriminação aqui referido, fato este que pode ser ilustrado com as palavras de Giroux e Simon (1995):

"À primeira vista, pode parecer remota a relação entre a cultura popular $e$ a pedagogia aplicada à sala de aula. A cultura popular é organizada em torno do prazer $e$ da diversão, enquanto $a$ pedagogia é definida principalmente em termos instrumentais. A cultura popular situa-se no terreno cotidiano, ao passo que a pedagogia geralmente legitima $e$ transmite a linguagem, os códigos $e$ os valores da cultura dominante. A cultura popular é apropriada pelos alunos $e$ ajuda $a$ validar suas vozes $e$ experiências, enquanto a pedagogia valida as vozes do mundo adulto, bem 
como o mundo dos professores $e$ administradores de escolas)."

A citação a seguir, tomada a Goodson (1995,pág.25), reforça, por outro ângulo, as palavras acima, ao abordar a forma como a educação musical tem tratado, muitas vezes, a contradição existente entre as manifestações musicais de nossas culturas:

"A teoria curricular para o treinamento de professores de música reforçou, com freqüência, esta dicotomia [ música erudita/música popular]. Brocklehurst (1962,p.55), por exemplo, afirma que: 0 objetivo primeiro da educação musical é fazer gostar da boa música $e$ compreendê-la. É certamente tarefa dos mestres esforçar-se ao máximo para prevenir os jovens de se tornarem presas fáceis dos fornecedores de música popular comercializada."

A citação acima contém diversos aspectos que merecem análise, e podemos destacar dois desses aspectos para um breve comentário. Primeiramente, podemos ressaltar que a própria formação dos professores de música tem se incumbido de conservar, sem criticar, essas concepções discriminatórias, como a dicotomia música erudita/música popular. Um currículo concebido em moldes da pedagogia crítica integraria necessariamente toda e qualquer concepção de música, promoveria a comparação e o confronto dessas concepções e a ampliação do próprio conceito de música para esses professores em 
formação.Em segundo lugar, podemos ressaltar, na afirmativa de Brocklehurst, contida na citação acima, a postura discriminatória que transparece na pretensão de a educação musical determinar e selecionar a "boa" música, afastando os jovens de outras manifestações musicais. A crença em um professor que detém todo o conhecimento e que, portanto, deve decidir o que os alunos devem ou não conhecer, é também flagrante no exemplo citado.

A exclusão "a priori" da "música popular comercializada", ou seja, daquela que é divulgada pela mídia, representa uma exclusão, também apriorística, da vivência musical de grande parte dos alunos. Contrariamente, a inclusão desse repertório como objeto efetivo de conhecimento e análise propicia uma oportunidade de revalorização do mesmo pelos educandos, assim como demonstra o respeito pelas suas experiências musicais cotidianas (Souza, 1997).Formulamos, então, as seguintes perguntas, aplicáveis a qualquer nível de ensino: Que espaço a apreciação musical tem ocupado nos currículos escritos e no cotidiano (currículo em ação) das instituições em que se ensina música, no Brasil? Que objetivos e que conteúdo tem a apreciação musical nesses casos? Observa-se que, na maioria das situações, a apreciação musical ocupa pouco espaço, utiliza repertório restrito e discriminatório e não é utilizada como efetiva atividade de construção de conhecimento musical, mas como atividade ilustrativa, superficial e periférica às demais atividades de educação musical. No trabalho com 
apreciação musical que venho desenvolvendo há alguns anos, tenho utilizado a apreciação como uma atividade de escuta que confere sentido ao material sonoro percebido, possibilitando uma compreensão da forma. Com base na fenomenologia da música, tenho considerado forma como a estrutura da música tal como é percebida e compreendida pelo ouvinte, ou seja, tenho tratado a forma não do possível ponto de vista do compositor, mas do ponto de vista do ouvinte.Cabe ressaltar, aqui, que a apreciação pode ter encaminhamentos diversos, e que o trabalho a que me referi acima, e que venho desenvolvendo há algum tempo, não representa, nem pretende representar, a única possibilidade de se conduzir a escuta na educação musical, em qualquer nível. Representa, contudo, uma possibilidade de escuta efetivamente comprometida com a construção do conhecimento musical, passível, inclusive, de ser submetida a abordagens de avaliação, segundo critérios objetivos (Hentschke, 1994).

$\mathrm{Na}$ proposta de apreciação musical com que tenho trabalhado, e coerentemente com a postura filosófica que tenho adotado em relação a educação e a currículo, considero que a compreensão (estruturação) da forma pelo ouvinte se dá de maneiras diversas, podendo, portanto ser alvo de diversas abordagens nos currículos de música, como resultado da interação de escutas diversas e de materiais sonoros diversos. Considero, assim, que o uso apenas do repertório tonal, ou daquele 
repertório considerado "tradicional", não oferece possibilidade de ampliação da escuta, da percepção, da compreensão da forma, tal como foi definida acima. Ao contrário, em uma perspectiva da pedagogia crítica, a utilização de repertórios diversificados, baseados em diferentes sistemas e processos composicionais, conduzem a escutas diversas e contrastantes entre si, possibilitando que a estruturação da música seja percebida através de parâmetros diversos, tais como espaço musical (constituído de estratos, horizontes, níveis, superfícies de baixo, alto e médio relevo, etc, segundo conceituação tomada a Cliffton, 1983), tempo, texturas, timbres ou outros.

A comparação de materiais sonoros é considerada, na abordagem de apreciação musical que venho desenvolvendo, um procedimento básico. Constatamos, contudo, que os currículos da área de música não têm, freqüentemente, oferecido ou previsto, em suas atividades, conteúdos, repertórios, etc, campo fértil para o contraste de materiais sonoros e de concepções musicais, reduzindo, assim, segundo nossa concepção, as possibilidades de uma apreciação musical rica, embasada na comparação.

A proposta para apreciação musical que estou aqui, rudimentarmente, descrevendo, é convergente com diversos trabalhos e com diversas concepções educacionais, tanto da área da Educação Geral, quanto da área da Educação Musical. Podemos, por exemplo, considerar o 
modelo educacional proposto por Swanwick (1994), que considera, como atividades básicas para qualquer planejamento de educação musical, a apreciação, a criação e a interpretação. A posição do referido autor é convergente com a nossa, na medida em que considera a apreciação como atividade essencial e intrínseca ao processo de construção do conhecimento musical. Observamos, contudo, que a apreciação musical é pouco praticada, de forma planejada e sistemática, em grande número de situações, nos diversos níveis de ensino de música, seja no ensino do instrumento, no âmbito de disciplinas como história da música, composição e outras. O uso da apreciação, freqüentemente, é omitido, praticado de forma apenas "intuitiva", sem qualquer respaldo teórico de professor, ou, ainda, praticado de forma apenas "ilustrativa", sem qualquer pretensão de construir, a partir da apreciação, um corpo conceitual que interfira, produtivamente, na construção do conhecimento musical, na criação musical, na "performance".

Outras propostas e modelos, no âmbito da educação musical, são também convergentes com a abordagem aqui proposta para a apreciação musical. Embora não mencione, especificamente, a apreciação musical, as diretrizes curriculares que apresento em minha tese de doutorado (Freire, 1992), são absolutamente articuladas com uma visão da apreciação musical como a aqui descrita, uma vez que as referidas diretrizes não abrem mão 
de um efetivo conhecimento musical construído criticamente, e de um efetivo compromisso com a cultura local.

Também Mertz (1998.), ao descrever alguns princípios para a formação de professores de música, enfatiza a necessidade de abordar, perceber e compreender distintos repertórios, sem abrir mão, também, de um envolvimento necessário com as manifestações musicais da cultura local.

Tomando, pois, como pressuposto, que a apreciação musical é instrumento precioso e imprescindível, na construção do conhecimento musical, e que o comprometimento com as manifestações musicais das culturas locais é também imprescindível, consideramos que a apreciação musical, embasada prioritariamente nas culturas brasileiras, deva ser componente indispensável em qualquer planejamento curricular.

Consideramos, ainda, que a apreciação deva ser, uma perspectiva da pedagogia crítica, apoiada, principalmente, na comparação, a partir do confronto de materiais musicais contrastantes, de forma a permitir:

- a elaboração de conceitos

- a compreensão da forma, como resultante da articulação de procedimentos estruturais básicos ( repetição, contraste, variação, adjunção, segundo Koellreutter, 1987), apreciada a partir de parâmetros diversos ( 
tais como textura, tempo, espaço musical etc)

a utilização da escuta como apoio, fundamento ou ponto de partida para atividades de criação musical, de interpretação musical ou para atividades teóricas

- a compreensão das diferenças culturais e musicais

Consideramos, finalmente, que a apreciação, para uma efetiva contribuição à formação musical do educando, deve seguir os seguintes princípios, aplicáveis a qualquer nível de ensino de música:

- respeitar a cultura dos alunos

- ampliar o universo de escuta do aluno, ainda que o ponto de partida seja a música que o aluno traz do seu cotidiano

- conduzir à elaboração crítica de conceitos

- conduzir à reflexão, contribuindo para a criação musical e para a interpretação musical

- conduzir à construção de conhecimento musical ( conhecimento crítico, criativo, inovador e não discriminador)

As questões que Giroux e Simon (1995) formulam podem, aqui, ser tomadas como um convite, final, à reflexão:

1) Que relação meus alunos vêem entre o trabalho que fazemos em classe e as vidas que eles levam fora da sala de aula? 
2) Seria possível incorporar aspectos da cultura vivida dos alunos ao trabalho de escolarização, sem simplesmente confirmar aquilo que já sabem?

3) Seria possível fazê-lo sem banalizar os objetos e relações que são importantes para os alunos?

4) E seria possível fazê-lo sem discriminar determinados grupos de alunos como marginais, exóticos e "outros" dentro de uma cultura hegemônica?

Consideramos que essas questões que Giroux abre são de grande importância para nós, educadores musicais de todos os níveis, e que tocam em pontos sensíveis para nós, seja na elaboração de currículos, seja no planejamento cotidiano de nossas aulas, ou seja, a necessidade de considerarmos, respeitarmos e incluirmos as culturas de nossos alunos, o que, certamente, abrange as manifestações musicais de suas vidas fora das instituições de ensino.

A apreciação musical, portanto, se embasada em uma pedagogia crítica, não poderá prescindir da riqueza que a contraposição de práticas musicais diversas proporciona, tomando, então, essa diversidade como ponto de partida para a comparação, para o contraste, para construção de conhecimento musical e musicológico, e para a construção da própria visão de mundo dos alunos, uma vez que não estará dissociada de uma compreensão dos diferentes papéis e valores que a música desempenha na sociedade. 


\section{Referências bibliográficas}

CLIFFTON, Thomas. Music as Heard. A Study in Applied Phenomenology. New Haven: Yale University Press, 1983.

DOMINGUES, José Luiz. Interesses humanos e paradigmas curriculares. Revista Brasileira de Estudos Pedagógicos, Brasília, 678 (156): 351 366, mai./ago. 1986.

FREIRE, Vanda Lima Bellard. Música e sociedade. Uma perspectiva histórica e uma reflexão aplicada ao ensino superior de música. Tese de Doutorado. Rio de Janeiro: Universidade Federal do Rio de Janeiro, 1992. . Educação

Musical no Brasil: Inovação e Tradição. 0 Bacharelado. Anais do III Encontro Anual da ABEM. Salvador, 1994.

GIROUX, Henry e SIMON, Roger. Cultura Popular e Pedagogia Crítica: a vida cotidiana como base para o conhecimento curricular.In. Moreira, Antônio Flávio e Silva, Tomaz Tadeu (Orgs.). Currículo, Cultura e sociedade. São Paulo: Cortez, 1995.

GOODSON, Ivor F. Currículo: Teoria e História. Petrópolis, RJ: Vozes, 1995.

HENTSCHKE, Liane. Avaliação do Conhecimento Musical dos Alunos.. In Anais do III Encontro Anual da ABEM. Salvador, 1994. KOELLREUTTER, Hans Joachimlntrodução à Estética e à composição musical contemporânea. Porto Alegre: Movimento, 1987. 
MERTZ, Margaret. Some Thoughts on Music Education in a Global Culture. International Journal of Music Education, n.2, p 72-772, 1998.

SAVIANI, Dermeval. Tendências e Correntes da Educação Brasileira. In Mendes, D. Trigueiro (Org.). Filosofia da Educação Brasileira. São Paulo: Civilização Brasileira, 1989.

SOUZA, Jusamara. Transformações globais e respostas da Educação Musical. Anais do I Encontro Regional Sul da ABEM. Londrina, 1997. SWANWICK,Keith. Musical Knowledge: intuition, analysis and music education. London:

Routledge, 1994. 